\title{
Inhibition of phosphatidylinositol 3-kinase/Akt and histone deacetylase activity induces apoptosis in non-small cell lung cancer in vitro and in vivo
}

\author{
Chadrick E. Denlinger, MD, Brian K. Rundall, DO, and David R. Jones, MD
}

From the Department of Surgery, University of Virginia, Charlottesville, Va.

This study was supported by grants to D.R.J (National Cancer Institute CA83920 and the American Association for Cancer Research) and to C.E.D. (National Cancer Institute F32 CA101497).

Read at the Eighty-fifth Annual Meeting of The American Association for Thoracic Surgery, San Francisco, Calif, April 10-13, 2005.

Received for publication April 10, 2005; revisions received June 6, 2005; accepted for publication June 16, 2005.

Address for reprints: David R. Jones, MD, Department of Surgery, Box 800679, University of Virginia, Charlottesville, VA 229080679 (E-mail: djones@ virginia.edu).

J Thorac Cardiovasc Surg 2005;130:1422-9

$0022-5223 / \$ 30.00$

Copyright () 2005 by The American Association for Thoracic Surgery

doi:10.1016/j.jtcvs.2005.06.051
Objective: Resistance to histone deacetylase inhibitors in non-small cell lung cancer is mediated in part through activation of nuclear factor- $\kappa \mathrm{B}$ through a phosphatidylinositol 3-kinase/Akt-dependent pathway. We hypothesize that inhibition of phosphatidylinositol 3-kinase/Akt will sensitize non-small cell lung cancer cells to histone deacetylase inhibitor-induced apoptosis.

Methods: Tumorigenic non-small cell lung cancer cell lines H157, H358, H460, and A549 were treated with nothing, the histone deacetylase inhibitor butyrate, the phosphatidylinositol 3-kinase/Akt inhibitor LY294002, or both compounds. Nuclear factor- $\kappa \mathrm{B}$ activity was assessed by reporter gene assays and reverse transcriptasepolymerase chain reaction of the nuclear factor- $\kappa \mathrm{B}$ dependent genes $c I A P-2, B f / / A 1$, and $M n S O D$. Whole cell extracts were immunoblotted for phospho-Akt, Akt, and phospho-ser/thr-Akt substrate. Cell death and apoptosis were measured by crystal violet staining, caspase-3 activity, and DNA fragmentation. A549 non-small cell lung cancer xenografts were created in athymic nude mice, and tumor growth was assessed after treatments as noted above. Explanted tumors underwent terminal deoxynucleotide transferase-mediated dUTP nick-end labeling and Western blot analyses for apoptosis assessment and drug target validation, respectively.

Results: Butyrate activated nuclear factor- $\kappa \mathrm{B}-$ dependent transcription, and LY294002 abrogated this effect. Combined treatment induced more apoptosis and cell death in vitro compared with either drug alone as measured by caspase-3, DNA fragmentation, and clonogenic survival. Combined butyrate and LY294002 was tumoristatic in vivo, but all other xenografts grew. This decreased tumor growth correlated with more apoptosis in the xenografts treated with combined therapy. Tumor levels of phospho-Akt and acetylated histone H3 were decreased and increased, respectively, in xenografts treated with combined therapy.

Conclusions: Combined histone deacetylase inhibitor and phosphatidylinositol 3kinase/Akt pathway inhibition sensitized non-small cell lung cancer xenografts to apoptosis. Further investigations of this combined therapy are warranted as new pharmacologic phosphatidylinositol 3-kinase/Akt pathway inhibitors are developed.

$\mathrm{W}$ e and others previously showed that the inflammatory and anti-apoptotic transcription factor, nuclear factor $(\mathrm{NF})-\kappa \mathrm{B}$, plays a significant role in the resistance of non-small cell lung cancer (NSCLC) to chemotherapy. ${ }^{1-3}$ Direct molecular inhibition of NF- $\kappa \mathrm{B}$ using an adenovirally delivered inhibitor of NF- $\kappa$ B dramatically sensitizes NSCLC cells to apoptosis induced by traditional chemotherapy agents such as gemcitabine, as well as novel biologic agents including the histone deacetylase inhibitors (HDIs) butyrate and suberoylanilide hydroxamic acid. ${ }^{1,4}$ Although adenoviral delivery of an inhibitor of NF- $\kappa \mathrm{B}$ may be efficacious in preclinical studies, clinical application is conceptually difficult and problematic for a number of reasons. 


\section{Abbreviations and Acronyms \\ GSK $\beta=$ phospho-ser/thr-Akt substrate \\ HDI $=$ histone deacetylase inhibitor \\ LY $=$ LY294002 \\ $\mathrm{NF}-\kappa \mathrm{B}=$ nuclear factor $-\kappa \mathrm{B}$ \\ NSCLC = non-small cell lung cancer \\ PI3K = phosphatidylinositol 3-kinase \\ RT-PCR = reverse transcriptase-polymerase chain reaction \\ TUNEL = terminal deoxynucleotide transferase- mediated dUTP nick-end labeling}

Activation of NF- $\kappa \mathrm{B}$ occurs through a number of disparate cell signaling pathways that include ligands binding surface receptors and stress responses emanated from the nucleus in response to DNA damage. ${ }^{5}$ It has been shown that the phosphatidylinositol 3-kinase (PI3K)/Akt pathway activates NF- $\kappa \mathrm{B}$ at both the cytoplasmic and nuclear levels. ${ }^{4,6,7}$ The PI3K family of membrane-bound protein kinases are stimulated directly or indirectly by cell surface receptor tyrosine kinases that respond to extracellular growth signals. ${ }^{8}$ The biologic consequences of Akt activation collectively support cell survival through inhibition of the pro-apoptotic proteins BAD, caspase-9, and forkhead, in addition to activating the anti-apoptotic transcription factor NF- $\kappa$ B. ${ }^{9-11}$ Recently, we demonstrated that PI3K/Akt has an important role in activating NF- $\kappa \mathrm{B}$ after treatment with HDIs. ${ }^{4}$

HDIs have been shown to induce growth arrest, differentiation, and apoptosis in malignant cells and are now the focus of phase I and II trials either alone or in combination with other compounds. We and others previously demonstrated that treatment of NSCLC with HDIs as single-agent therapy is ineffective in vitro and in vivo. ${ }^{12-14}$ This relates, in part, to the activation of NF- $\kappa \mathrm{B}$ by the HDIs, which attenuates proapoptotic signals induced by these compounds. Realizing that HDIs activate NF- $\kappa \mathrm{B}$ through signal transduction pathways involving PI3K/Akt, we hypothesized that the pharmacologic inhibition of PI3K/Akt using LY294002 (LY) would sensitize NSCLC to HDI-induced apoptosis in our in vitro and in vivo NSCLC model systems.

\section{Materials and Methods}

\section{Cell Culture Reagents and Plasmids}

Four cell lines representing different NSCLC histologic subtypes (NCI-H157 [squamous cell], NCI-H358 [bronchioloalveolar cell], NCI-H460 [large cell], and NCI-A549 [unknown histology]), obtained from the American Type Culture Collection, were cultured in Roswell Park Memorial Institute 1640 (Invitrogen, Carlsbad, Calif) supplemented with $10 \%$ fetal bovine serum (HyClone Laboratories, Logan, UT) and penicillin/streptomycin. The full-length
Ga14/p65-luciferase construct contains 4 Gal-4 DNA consensus binding sites derived from the yeast GAL-4 gene promoter cloned upstream of luciferase cDNA. The Gal4-p65 fusion protein consists of a yeast Gal-4 DNA-binding domain fused to full-length p65 (1-551) and was described previously. ${ }^{12}$ Antibodies against MnSOD and acetyl-H3 were obtained from Upstate Biotechnology (Lake Placid, NY). Antibodies against Akt, phospho-Akt, and phospho-ser/thr-Akt substrate (GSK $\beta$ ) were obtained from Cell Signaling (Beverly, Mass). The antibody against RNA Pol II (C-21) was obtained from Santa Cruz Biotechnology (Santa Cruz, Calif). Sodium butyrate and anti- $\beta$-tubulin antibodies were purchased from Sigma (St Louis, Mo), and LY was purchased from Calbiochem (La Jolla, Calif).

\section{Luciferase Reporter Gene Assays}

NSCLC cells at $60 \%$ to $80 \%$ confluency were transiently transfected with $0.3 \mu \mathrm{g}$ DNA per well using Polyfect (Qiagen, Valencia, Calif) according to the manufacturer's instructions. Six hours after the start of transfection, additional media containing the appropriate pharmacologic agents were added. Twenty-four hours after transfection, cells were washed once with $1 \times$ phosphatebuffered saline and lysed in luciferase reporter buffer (Promega, Madison, Wis). Cells were then snap-frozen at $-80^{\circ} \mathrm{C}$ and subsequently thawed in a $37^{\circ} \mathrm{C}$ water bath. Extracts were collected and cleared by centrifugation at $13,200 \mathrm{rpm}$. Protein concentrations were determined with a Pierce BCA protein assay kit reagent (Pierce, Rockford, Ill). Luciferase assays were performed by using the substrate D-Luciferin (Promega), and relative light units were measured with an Orion Microplate Luminometer, (Berthold Detection Systems, Pforzheim Germany). Luminescence was normalized to protein concentration, and values were reported as the mean \pm standard error of mean of triplicate experiments.

\section{Reverse Transcriptase-Polymerase Chain Reaction}

NCSLC cells were treated for 12 hours with nothing, butyrate (500 $\mu \mathrm{mol} / \mathrm{L}), \mathrm{LY}(25 \mu \mathrm{mol} / \mathrm{L})$, or both compounds. Cells were lysed with Trizol (Invitrogen), and proteins were extracted with chloroform. RNAs were precipitated with isopropanol and washed with $70 \%$ ethanol. cDNAs were created using the Advantage reverse transcriptase-polymerase chain reaction (RT-PCR) enzyme (Clontech, Palo Alto, Calif) and amplified by PCR using Platinum Taq (Invitrogen). The following primer pairs were used for the respective genes: $M n S O D$ : 5'-ATCGAAGCTTTTGAGCCGGGC AGTGTGC-3', 5'-ATCGCGGCCGCTATCTGGGCTGTAACAT-3', Bfl/Al: 5'-ATCGAAGCTT ACAGACTGTGAATTTGGA-3', 5'-ATCGCGGCCGCTCAACAGTATTGCTTCA-3', cIAP-2: 5'-TCTACATATTCAACTTTCCCCGCCGGG-3', 5'-AACTTTCTCCAGGTCCAAAATGAAT AA- $3^{\prime}$. As a control, GAPDH cDNA was amplified using the primers $5^{\prime}$-GTGAGGAGGGGAG ATTCAG-3' and 5'GCATCCTGGGCTACACTG-3'. PCR products were resolved on a $0.8 \%$ agarose gel.

\section{Western Immunoblot}

Whole cell lysates were prepared from cells treated as described, using the radioimmunoprecipitation assay lysis buffer. Proteins (50 $\mu \mathrm{g} / \mathrm{lane}$ ) were resolved on a $10 \%$ sodium dodecyl sulfate gel and transferred to nitrocellulose membranes (Bio-Rad, Hercules, Calif). Membranes were blocked in 5\% milk, triethanolamine- 
buffered saline, and $0.1 \%$ Tween for 1 hour and immunoblotted with primary antibodies against Akt, phospho-Akt, GSK $\beta$, and $\beta$-tubulin.

\begin{abstract}
Apoptosis Assays
NSCLC cells at $60 \%$ confluency were treated with the conditions as described for 24 hours. Caspase- 3 activity was determined by the addition of an APC-DEVD protein conjugate (Calbiochem) to cellular lysates containing $25 \mu \mathrm{g}$ of protein. Fluorescence of caspase-3-cleaved protein conjugates was detected on a microplate spectrophotometer SpectraMAX Gemini (Molecular Devices, Sunnyvale, Calif). DNA fragmentation was measured using the Cell Death Detection ELISA Plus kit (Roche, Indianapolis, Ind) according to the manufacturer's instructions.
\end{abstract}

\section{Cell Survival Assays}

NSCLC cells were thinly plated and then treated with nothing, butyrate $(500 \mu \mathrm{mol} / \mathrm{L})$, LY $(25 \mu \mathrm{mol} / \mathrm{L})$, or both compounds for 48 hours. Drug-containing media were removed, and cells were then incubated in drug-free media for 5 days. Colonies were then fixed and stained by sequentially incubating the cells in $1 \%$ glutaraldehyde and $0.5 \%$ crystal violet for 15 minutes each. Colonies were then counted per $6 \mathrm{~mm}^{2}$ in triplicate and are reported as percent cell survival.

\section{Xenograft Development and Treatment}

Experiments in this study were performed in accordance with a written protocol approved by our institutional animal care and use committee. Human NSCLC xenografts were generated in athymic nude mice (Taconic, Germantown, NY) by injecting $2 \times 10^{6}$ A549 cells suspended in serum-free Roswell Park Memorial Institute (100 $\mu \mathrm{L} /$ injection site) into each flank of the animal. Once the tumors achieved a volume of $0.5 \mathrm{~cm}^{3}$ the mice were randomized to receive no treatment $(\mathrm{n}=3$ mice $)$, butyrate $(8 \mathrm{mg} / \mathrm{mL}$ in drinking water) ( $\mathrm{n}=4 \mathrm{mice}), \mathrm{LY}(100 \mathrm{mg} / \mathrm{kg}$ intraperitoneally twice weekly) ( $n=4$ mice), or both butyrate and LY at the same doses $(\mathrm{n}=4$ mice). Tumors were measured, and volumes were calcu-

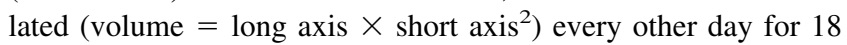
days. Data are expressed as the mean \pm standard error of mean. At the conclusion of the treatment period, mice were euthanized and tumors were harvested.

\section{Xenograft Tissue Analysis}

After euthanasia, xenografts were harvested and snap-frozen in liquid nitrogen. Apoptosis in the xenografts was determined by terminal deoxynucleotide transferase-mediated dUTP nick-end labeling (TUNEL) analysis. Western blot analysis was performed by homogenizing frozen tissue in radioimmunoprecipitation assay, resolving $50 \mu \mathrm{g}$ protein by sodium dodecyl sulfate-polyacrylamide gel electrophoresis and immunoblotting for Akt, phospho-Akt, acetylated histone H3, MnSOD, and RNA pol II.

\section{Statistical Analysis and Data Interpretation}

Where appropriate, statistical significance was determined by Student $t$ test or analysis of variance tests. The study design, data analysis, interpretation, and decision to submit this article for publication were not influenced by any outside funding agency.

\section{Results}

Inhibition of PI3K/Akt Reduces Histone Deacetylase Inhibitor-Induced Activation of NF- $\mathbf{B}$

To test the hypothesis that LY would abrogate the butyrateinduced upregulation of NF- $\kappa \mathrm{B}$, the transactivation potential of RelA/p65, the transcriptionally active NF- $\kappa$ B subunit, was determined through transient transfection assays in several NSCLC cell lines. In each of the 4 cell lines examined, butyrate dramatically enhanced the transactivation potential of RelA/p65, and this effect was significantly attenuated by the addition of LY (Figure 1, A).

To determine whether butyrate and LY had similar influences on endogenous NF- $\kappa \mathrm{B}-$ regulated genes, NSCLC cells were treated as noted and semiquantitative RT-PCR was performed. In each cell line, butyrate enhanced transcription of $M n S O D, B f l / A 1$, and $c I A P-2$ and the addition of LY suppressed transcription of these same genes to basal levels (Figure 1, B). Confirmation that LY was affecting its intended molecular target is demonstrated in Figure 1, $C$. Although butyrate did not affect phospho-Akt levels, LY did completely block Akt activity as measured by dramatic reductions in phospho-Akt and phospho-GSK $\beta$ levels.

Collectively, these data suggest that the HDI butyrate up-regulates the transcriptional activity of NF- $\kappa \mathrm{B}$ by enhancing the transactivation potential of RelA/p65 and that LY blocks this effect. Moreover, this correlates with the activation or repression of endogenous NF- $\kappa \mathrm{B}-$ dependent genes in NSCLC after treatment with butyrate or LY, respectively. Thus, HDI-mediated NF- $\kappa \mathrm{B}$ activation requires the presence of activated PI3K/Akt, but HDIs do not activate $\mathrm{PI} 3 \mathrm{~K} / \mathrm{Akt}$.

\section{Combined Histone Deacetylase Inhibitor and LY294002 Enhances Apoptosis in NSCLC}

We next sought to determine whether inhibition of histone deacetylase and PI3K/Akt activity would promote apoptosis in our NSCLC cell model. As shown in Figure 2, $A$ and $B$, there was significantly enhanced caspase-3 activation $(P \leq$ .002) and DNA fragmentation $(P \leq .013)$ after combined therapy relative to either compound alone. In an effort to establish that the induction of apoptosis in NSCLC after treatment with LY and butyrate correlated with cell death and that these cell death effects persisted, 48-hour cell survival assays were performed. NSCLC cells treated with both butyrate and LY had significantly less survival than cells treated with either butyrate or LY alone (Figure 2, C). These experiments provide a definitive biologic link (apoptosis) to the molecular events previously examined in Figure 1 and prior studies from our group and others. ${ }^{4,14}$

\section{Combined Butyrate and LY294002 Provides Synergistic Killing In Vivo}

It is increasingly recognized that alterations in signal transduction pathways and their resulting cellular biologic events 


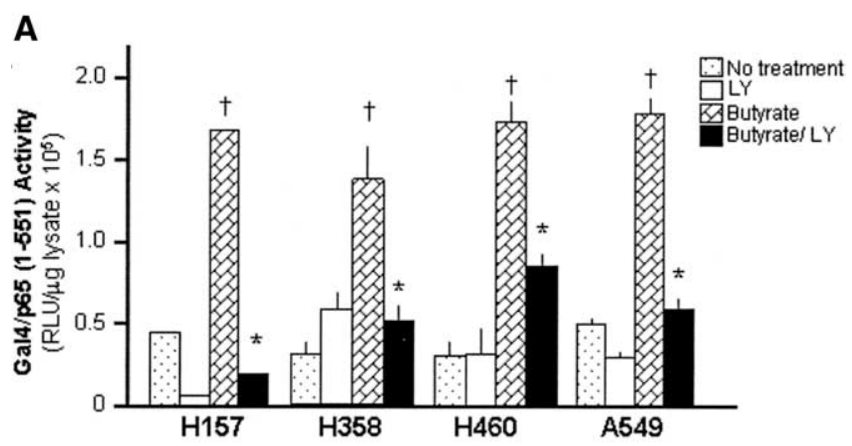

B

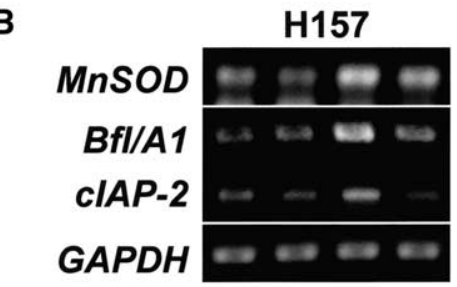

\section{H358}
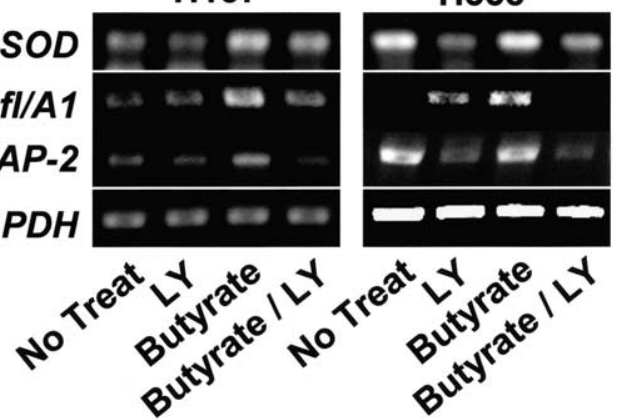

C

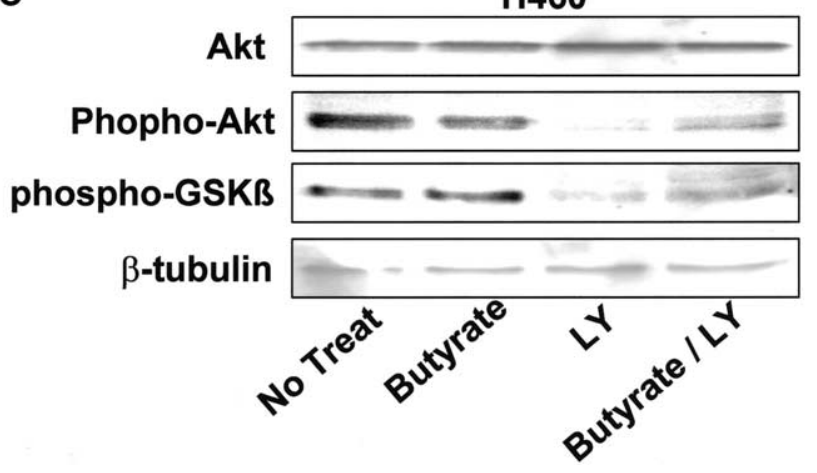

Figure 1. A, NSCLC cells were treated with nothing, butyrate, LY, or both drugs. NF- $\mathrm{B}$-dependent transcriptional activity was determined by (A) Gal4-p65 luciferase reporter genes and (B) transcription of MnSOD, BfI/A1, and cIAP-2 by RT-PCR. C, Identically treated cells were analyzed by Western blotting for the proteins Akt, phospho-Akt, acetyl-H3, and phospho-GSKB. ( $P \leq$ .006 vs no treatment, and ${ }^{*} P \leq .02$ vs butyrate.) $R L U$, Relative light unit.

may be dramatically different when experiments are performed solely in cell culture. To determine whether our in vitro observations would translate to a more clinically relevant model, we developed an NSCLC (A549) xenograft model. The A549 cell line was selected on the basis of prior xenograft studies performed in the laboratory in which the A549 xenografts were noted to have a more predictable
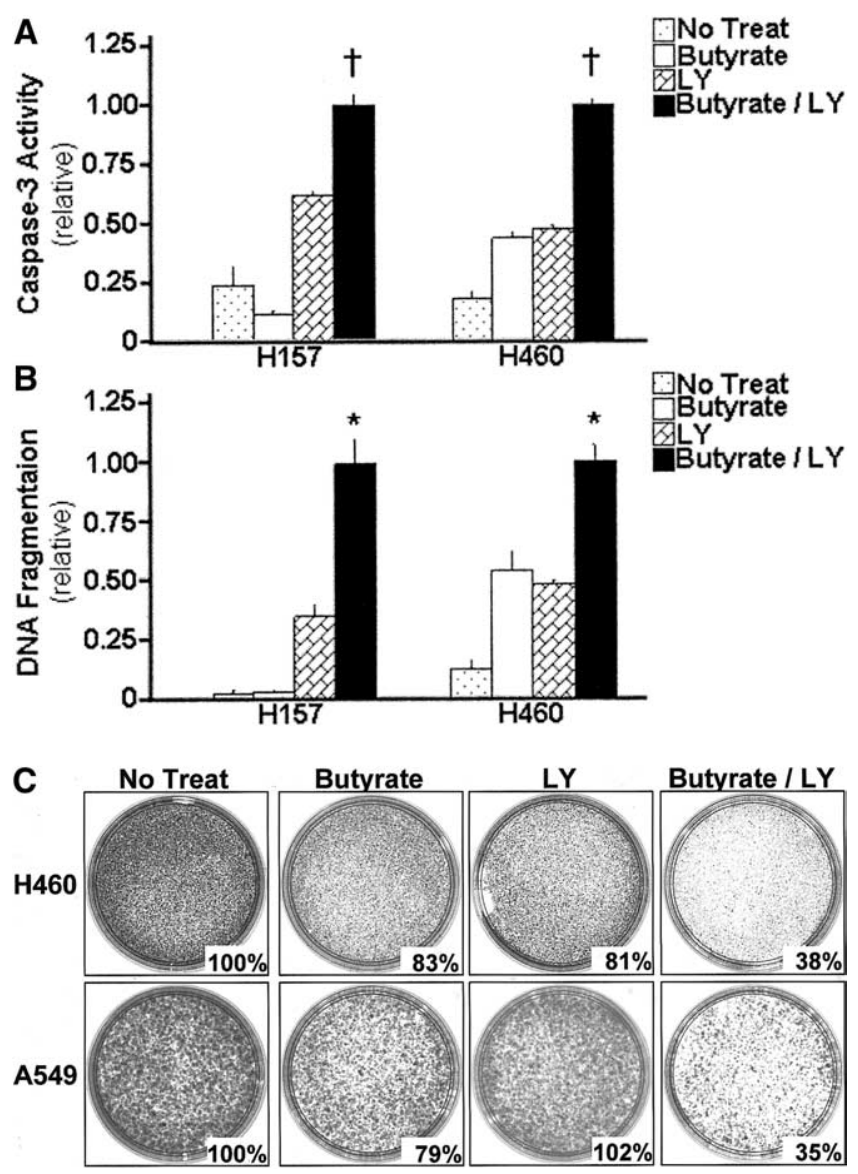

Figure 2. NSCLC cells were treated with nothing, butyrate (500 $\mu \mathrm{mol} / \mathrm{L}), \mathrm{LY}(25 \mu \mathrm{mol} / \mathrm{L})$, or both drugs, and apoptosis was measured by (A) caspase-3 activity and (B) DNA fragmentation. C, NSCLC cells were treated as above, and survival was determined by clonogenic survival (survival expressed relative to untreated controls). ( $+P \leq .002$ and ${ }^{*} P \leq .013$ vs all other treatment conditions.)

growth pattern relative to other xenografts created using NSCLC cells.

Combined systemic treatment with butyrate and LY resulted in significantly reduced tumor growth rates relative to untreated controls or tumors treated with either drug alone (Figure 3). This combinatorial treatment resulted in synergistic reduction in tumor growth compared with butyrate alone. Although xenografts treated with LY alone grew slightly slower over time, only the combined therapy resulted in essentially no tumor growth relative to the tumor volume at the initiation of treatment $(P \leq .005)$.

Although the treatment of NSCLC xenografts with both butyrate and LY completely inhibited tumor growth in vivo, it was unclear whether this was the result of cell-cycle arrest or the induction of apoptosis. To experimentally address this, TUNEL analysis was performed on explanted tumor 


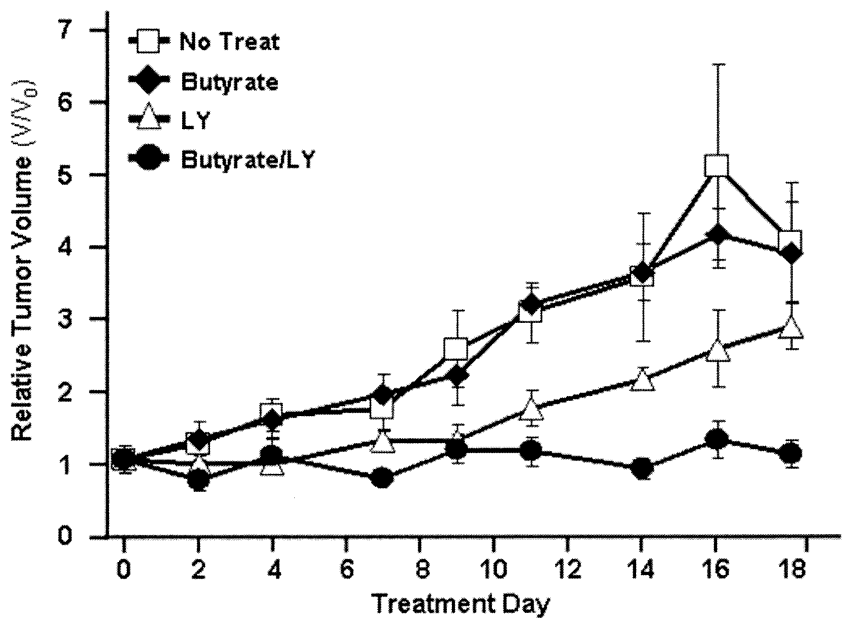

Figure 3. NSCLC xenografts were treated with nothing, butyrate $(8 \mathrm{mg} / \mathrm{mL}$ in drinking water), LY (100 mg/kg intraperitoneally twice weekly), or both drugs, and tumors were measured every other day. Volumes were calculated and expressed as relative tumor growth $(\mathrm{V} / \mathrm{Vo}) \pm$ standard error of mean $(P \leq .005)$.

xenografts. Combined treatment induced more apoptosis than treatment with either drug alone (Figure 4, A).

To confirm that butyrate and LY were in fact reaching the tumor and their intended molecular targets, Western blot analyses were performed on the tumor xenografts (Figure 4, $B$ ). As seen previously in experiments performed in vitro, the addition of LY depressed phospho-Akt levels without significantly affecting the overall levels of Akt. In each treatment condition, the addition of butyrate did not appear to have any significant effect on Akt or phospho-Akt levels. Xenografts from animals treated with butyrate demonstrated enhanced acetylation of histone $\mathrm{H} 3$, suggesting global tumor hyperacetylation. These target validation studies indicate that both butyrate and LY were active in the NSCLC xenografts. Collectively, these in vivo experiments provide "proof of principle" of our in vitro cell culture experiments.

\section{Discussion}

The majority of patients with NSCLC present with advanced stage disease and are commonly managed with systemic chemotherapy, either with or without the local treatment modalities of surgery or radiation. ${ }^{15}$ Currently available chemotherapeutic agents that nonspecifically target the DNA of rapidly dividing cells afford marginal patient survival benefit when used as isolated therapy. ${ }^{16,17}$ These sobering results have prompted an intense search for novel therapies that target intracellular or extracellular proteins that are relevant to each individual tumor and its biology.

Recently, interest in the more novel class of chemotherapeutic agents, the HDIs, has been generated on the basis of
No Add
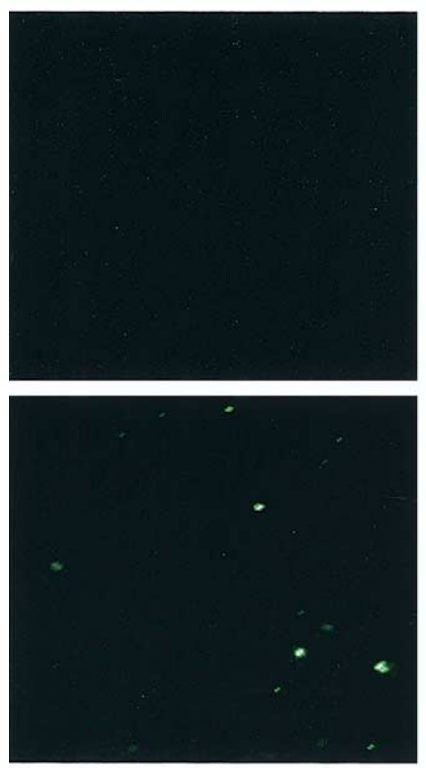

A LY
Butyrate
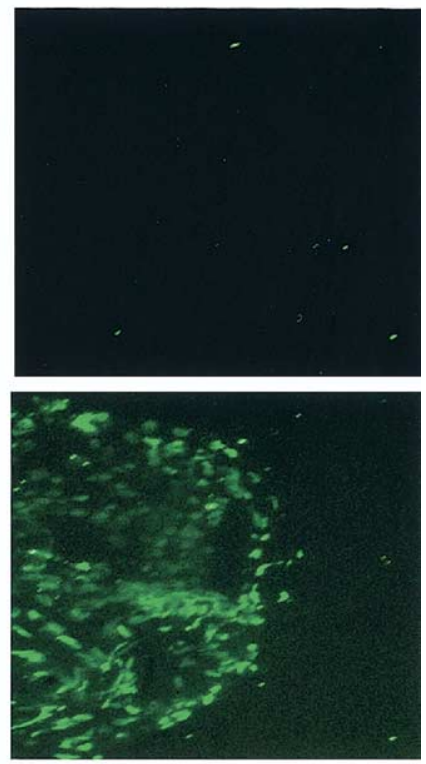

Butyrate / LY

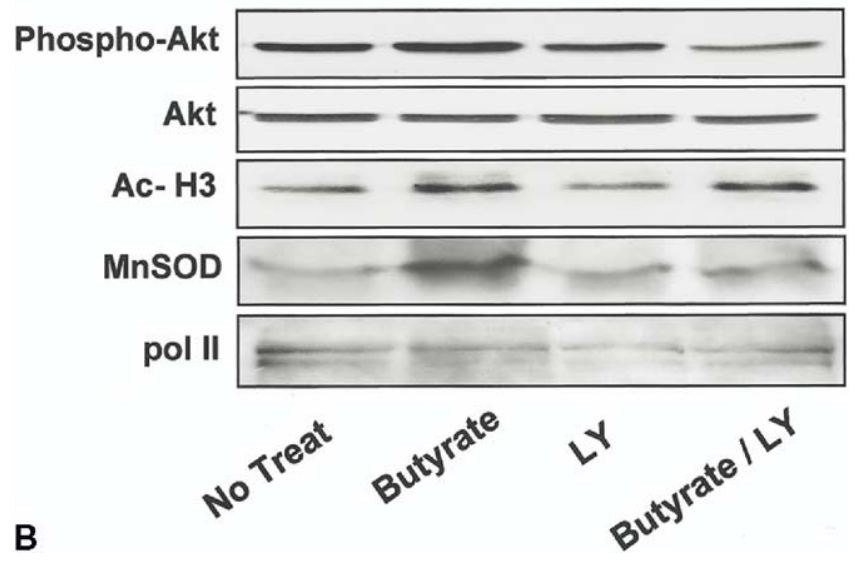

Figure 4. A, Xenografts were harvested and apoptosis was determined by TUNEL analysis. B, Western blots were performed on xenografts for phospho-Akt, Akt, acetyl-histone H3, MnSOD, and RNA pol II.

preclinical studies showing that these agents are capable of inducing cellular differentiation, apoptosis, and cell cycle arrest. ${ }^{18}$ A phase I clinical trial of the HDI depsipeptide, in patients with advanced-stage solid tumor malignancies including NSCLC, found that only 1 of 37 patients treated showed a clinical response. This single patient demonstrated greater than $50 \%$ reduction in the mediastinal, retroperitoneal, and supraclavicular adenopathy associated with metastatic renal cell carcinoma. ${ }^{19}$ Similarly, Kelly and colleagues $^{20}$ found that suberoylanilide hydroxamic acid, 
when used as a single agent resulted in limited clinical efficacy.

Chromatin hyperacetylation is thought to correlate with increased transcriptional activity. However, HDIs affect transcriptional activity of only $10 \%$ of the entire genome, and an equal number of genes are inhibited as are activated. ${ }^{21}$ Although mechanisms underlying biologic responses of malignant cells to HDI therapy remain poorly elucidated, previously described mechanisms of action include induction of cell-cycle arrest through p21 up-regulation and enhanced transcription of the tumor suppressor gene gelsolin. ${ }^{18}$

Genomic aberrations, typical of malignant transformation, have been studied in NSCLC. ${ }^{22}$ The most frequently amplified segment of DNA is located at chromosome $3 q 26.3$ in squamous cell carcinoma of the lung, and subsequent fluorescent in situ hybridization analysis found the second most frequently amplified gene was PI3K (second only to somatostatin). ${ }^{22}$ Further analyses have shown that $\mathrm{PI} 3 \mathrm{~K} /$ Akt is significantly overexpressed in $90 \%$ of NSCLC cell lines, ${ }^{23}$ and that $77 \%$ of all lung cancers overexpress the catalytic subunit of PI3K. ${ }^{24}$ The role of PI3K/Akt in lung carcinogenesis is further supported by the fact that both nicotine and 4-(methylnitrosamino)-1-(3-pyridyl)-1-butanone, another carcinogen found in tobacco smoke, enhance Akt activity. ${ }^{25}$ In addition, increased Akt activity has been suggested to have clinical prognostic significance independent of tumor stage. ${ }^{26,27}$ Collectively, these studies suggest that the PI3K/Akt pathway plays a role in the oncogenesis and progression of NSCLC.

The transcription factor NF- $\kappa \mathrm{B}$ is also activated by tobacco smoke through mechanisms similar to tumor necrosis factor-dependent activation, and the tobacco-related carcinogen 4-(methylnitrosamino)-1-(3-pyridyl)-1-butanone has been shown to induce neoplastic transformation of xenografted human bronchial endothelial cells. ${ }^{28,29} \mathrm{NF}-\kappa \mathrm{B}$ is a downstream target that is activated by Akt, which stimulates nuclear translocation of the transcriptionally active p50/p65 heterodimers and also is required for full up-regulation of the transactivation potential of RelA/p65. ${ }^{4,6} \mathrm{NF}-\kappa \mathrm{B}$ is also activated by chemotherapy, and its activation contributes significantly to the resistance of NSCLC to apoptosis induced by traditional chemotherapeutic agents as well as HDI therapy. $1,2,12,14,30$

In this study we addressed the hypothesis that pharmacologic inhibition of the PI3K/Akt pathway would inhibit NF- $\kappa$ B and sensitize NSCLC cells to apoptosis after histone deacetylase inhibition. As shown in Figure 1, butyrate dramatically activated NF- $\kappa \mathrm{B}$-dependent transcription in vitro, and this effect was blocked by LY. Subsequent studies correlated PI3K/Akt inhibition with the sensitization of NSCLC cells to butyrate-induced apoptosis both in vitro and in vivo (Figures 2 and 3). This combination therapy was also found to have synergistic tumoricidal effects in our in vivo model. Our results are similar to those reported by other groups, although in different solid tumors. Wang and colleagues $^{31}$ found that combined butyrate and wortmannin (another PI3K/Akt inhibitor) resulted in significant in vitro and in vivo apoptotic cell death in a colon cancer model. Rahmani and colleagues ${ }^{32}$ found that combined LY and butyrate also induced significant apoptosis on human leukemic cells, but that the effect of the PI3K inhibitor LY appeared to be mediated through a MAP kinase-dependent pathway and not directly through Akt.

A necessary component of drug discovery and the associated preclinical studies is the determination of target validation in the tissue or tumor of interest. As shown in this study both butyrate and LY appeared to reach the tumor and resulted in the perturbation of their intended molecular targets. It is certainly possible, and indeed likely, that other proteins that we did not screen for were also affected by these compounds and that these effects may have contributed to the observed apoptosis. For a more complete picture of all affected molecules by this combined therapy, future studies would need to have either gene-array or proteomic analyses performed on the explanted tumor.

This study builds on previous studies that have shown that direct molecular inhibition of NF- $\kappa$ B sensitizes NSCLC to chemotherapy and HDI-induced apoptosis. ${ }^{1,2,4}$ More recently, we showed that pharmacologic inhibition of NF- $\kappa \mathrm{B}$ with the proteasome inhibitor Velcade (Millennium Pharmaceuticals, Cambridge, Mass) also sensitizes NSCLC to HDI-induced apoptosis. ${ }^{30}$ In an effort to potentially expand potential drug targets we sought to look upstream at signal transduction pathways, like PI3K/Akt, that activate NF- $\kappa$ B. The 2 well-known PI3K/Akt inhibitors, LY and Wortmannin, are both insoluble in water and thus are unlikely to be used clinically. More recently, however, naltrindole, a $\delta$-opioid receptor antagonist similar to naloxone, has been shown to inhibit Akt phosphorylation at doses within the same order of magnitude of what has been achieved in animals. ${ }^{33}$ Castillo and colleagues ${ }^{34}$ also identified several phosphatidylinositol ether lipid analogues that inhibited Akt activity at low concentrations and enhanced apoptosis by 20- to 30-fold in cancer cell lines that express high levels of Akt.

\section{Conclusion}

This study indicates that combined inhibition of histone deacetylase activity and PI3K/Akt induces apoptosis in NSCLC both in vitro and in vivo. We also provided important preliminary target validation evidence for each compound of this combined treatment approach. This combined treatment approach may benefit patients with NSCLC as more soluble inhibitors of the PI3K/Akt pathway are developed and become commercially available. 


\section{References}

1. Jones DR, Broad DR, Madrid LV, Baldwin AS, Mayo MW. Inhibition of NF- $\kappa$ B sensitizes non-small cell lung cancer cells to chemotherapyinduced apoptosis. Ann Thorac Surg. 2000;70:930-7.

2. Jones DR, Broad RM, Comeau LD, Parsons SJ, Mayo MW. Inhibition of nuclear factor $\kappa \mathrm{B}$ chemosensitizes non-small cell lung cancer through cytochrome c release and caspase activation. $J$ Thorac Cardiovasc Surg. 2002;123:310-7.

3. Singh RP, Malikarjuna GU, Sharma G, Dhanalakshumi S, Tyagi AK, Chan DFC, et al. Oral silibinin inhibits lung tumor growth in athymic nude mice and forms a novel chemocombination with doxorubicin targeting nuclear factor kB-mediated inducible chemoresistance. Clin Cancer Res. 2004;10:8641-7.

4. Mayo MW, Denlinger CE, Broad RM, Yeung F, Reily ET, Shi Y, et al. Ineffectiveness of histone deacetylase inhibitors to induce apoptosis involves the transcriptional activation of NF-kappa B through the Akt pathway. J Biol Chem. 2003;278:18980-9.

5. Denlinger CE, Rundall BK, Jones DR. Modulation of anti-apoptotic signaling pathways in non-small cell lung cancer: the role of NF- $\kappa \mathrm{B}$. Semin Thorac Cardiovasc Surg. 2004;16:28-39.

6. Romashkova JA, Makorov SS. NF- $\kappa$ B is a target of Akt in antiapoptotic PDGF signaling. Nature. 1999;401:86-90.

7. Madrid LV, Mayo MW, Reuther JY, Baldwin AS. Akt stimulates the transactivation potential of the Rel A/p65 subunit of NF- $\kappa$ B through utilization of the $\mathrm{I} \kappa \mathrm{B}$ kinase and activation of the mitogen-activated protein kinase p38. J Biol Chem. 2001;276:18934-40.

8. Vivanco I, Sawyers CL. The phosphatidylinositol 3-kinase-Akt pathway in human cancer. Nat Rev Cancer. 2002;2:489-501.

9. Datta SR, Dudek H, Tao X, Masters S, Fu H, Gotoh Y, et al. Akt phosphorylation of BAD couples survival signals to the cell-intrinsic death machinery. Cell. 1997;91:231-41.

10. Brunet A, Bonni A, Zigmond MJ, Lin MZ, Juo P, Hu LS, et al. Akt promotes cell survival by phosphorylating and inhibiting a Forkhead transcription factor. Cell. 1999;96:857-68.

11. Cardone MH, Ray N, Stennicke HR, Salvensen GS, Franke TF, Stanbridge E, et al. Regulation of cell death protease caspase- 9 by phosphorylation. Science. 1998;282:1318-21.

12. Denlinger CE, Keller MD, Mayo MW, Broad, RM, Jones DR. Combined histone deacetylation and proteosome inhibition enhances apoptosis in non-small cell lung cancer. J Thorac Cardiovasc Surg. 2004;127:1078-86.

13. Rundall BK, Denlinger CE, Jones DR. Combined histone deacetylase and NF-kappaB inhibition sensitizes non-small cell lung cancer to cell death. Surgery. 2004;136:416-25.

14. Maxhimer JB, Reddy RM, Zou J, Cole GW, Schrump DS, Nguyen DM. Induction of apoptosis of lung and esophageal cancer cells treated with the combination of histone deacetylase inhibitor (trichostatin A) and protein kinase $\mathrm{C}$ inhibitor (calphostin C). J Thorac Cardiovasc Surg. 2005;129:53-63.

15. Jemal A, Murray T, Ward E, Samuels A, Tiwari RC, Ghafoor A, et al. Cancer statistics 2005. CA Cancer J Clin. 2005;55:10-30.

16. Non-small cell lung cancer collaborate group. Chemotherapy in nonsmall cell lung cancer: a meta-analysis using updated data on individual patients from 52 randomized clinical trials. Br Med J. 1995;311: 899-909.

17. Schiller JH, Harrington D, Belani CP, Langer C, Sandler A, Krook J, et al. Comparison of four chemotherapy regimens for advanced nonsmall-cell lung cancer. N Engl J Med. 2002;346:92-8.

18. Marks PA, Rifkind RA, Richon VM, Breslow R, Miller T, Kelly WK Histone deacetylases and cancer: causes and therapies. Nat Rev Cancer. 2002;1:194-202.

19. Sandor V, Bakke S, Robey RW, Kang MH, Blagosklonny MV, Bender $\mathrm{J}$, et al. Phase I trial of the histone deacetylase inhibitor, depsipeptide (FR901228, NSC 63-176), in patients with refractory neoplasms. Clin Cancer Res. 2002;8:718-28.

20. Kelly WM, Richon VM, O'Conner O, Curley T, MacGregor-Curtelli $\mathrm{B}$, Tong W, et al. Phase I clinical trial of histone deacetylase inhibitor: suberoylanilide hydroxamic acid administered intravenously. Clin Cancer Res. 2003;9:3578-88.

21. Glasser KB, Starver MJ, Waring JF, Stender J, Ulrich RG, Davidsen SK. Gene expression profiling of multiple histone deacetylase
(HDAC) inhibitors: defining a common gene set produced by HDAC inhibition in T24 and MDA carcinoma cell lines. Mol Cell Ther. 2003;2:151-63.

22. Massion PP, Kuo WL, Stokoe D, Olshen AB, Treseler PA, Chin K, et al. Genomic copy number analysis of non-small cell lung cancer using array comparative genomic hybridization: implications of the phosphatidylinositol 3-kinase pathway. Cancer Res. 2002;62:3636-40.

23. Brognard J, Clark AS, Ni Y, Dennis PA. Akt/protein kinase B is constitutively active in non-small cell lung cancer cells and promotes cellular survival and resistance to chemotherapy and radiation. Cancer Res. 2001;61:3986-97.

24. Lin X, Bohle AS, Dohrmann P, Leuschner I, Schulz A, Kremer B, et al. Overexpression of phosphatidylinositol 3-kinase in human lung cancer. Langenbecks Arch Surg. 2001;386:293-301.

25. West KA, Brognard J, Clark AS, Linnoila IR, Yang X, Swain SM, et al. Rapid Akt activation by nicotine and a tobacco carcinogen modulates the phenotype of normal human airway epithelial cells. J Clin Invest. 2003;111:81-90.

26. Gupta AK, Soto DE, Feldman MD, Goldsmith JD, Mick R, Hahn SM, et al. Signaling pathways in NSCLC as a predictor of outcome and response to therapy. Lung. 2004;182:151-62.

27. David O, Jett J, LeBeau H, Dy G, Hughes J, Friedman M, et al. Phospho-Akt overexpression in non-small cell lung cancer confers significant stage-independent survival disadvantage. Clin Cancer Res. 2004; 10:6865-71.

28. Anto RJ, Muckopadhyay A, Shishodia S, Gary C, Aggarwal B. Cigarette smoke condensate activates nuclear factor $\mathrm{kB}$ through phosphorylation and degradation of $\mathrm{I} \kappa \mathrm{B} \alpha$ : correlation with induction of cyclooxygenase-2. Carcinogenesis. 2002;23:1511-8.

29. Klein-Szanto AJ, Iizasa T, Momiki S, Garcia-Palazzo I, Caamano J, Metcalf R, et al. A tobacco-specific N-nitrosamine or cigarette smoke condensate causes neoplastic transformation of xenografted human bronchial endothelial cells. Proc Natl Acad Sci. 1992;89:6693-7.

30. Denlinger CE, Rundall BK, Keller MD, Jones DR. Proteasome inhibition sensitizes non-small cell lung cancer to gemcitabine-induced apoptosis. Ann Thorac Surg. 2004;78:1207-14.

31. Wang Q, Li N, Wang X, Kim MM, Evers BM. Augmentation of sodium butyrate-induced apoptosis by phosphatidylinositol 3'-kinase inhibition in the KM20 human colon cancer cell line. Clin Cancer Res. 2002;8:1940-7.

32. Rahmani M, Yu C, Reece E, Ahmed W, Hirsch K Dent P, et al. Inhibition of PI-3 kinase sensitizes human leukemic cells to histone deacetylase inhibitor mediated apoptosis through p44/p42 MAP kinase inactivation and abrogation of $\mathrm{p} 21$ (CIP/WAF1) induction rather than AKT inhibition. Oncogene. 2003;22:6231-42.

33. Chen YL, Law PY, Horace HL. Inhibition of Akt/protein kinase B signaling by naltrindole in small cell lung cancer cells. Cancer Res. 2004;64:8723-30.

34. Castillo SS, Brognard J, Petukhov PA, Zhang C, Tsurutani J, Granville $\mathrm{CA}$, et al. Preferential inhibition of Akt and killing of Akt-dependent cancer cells by rationally designed phosphatidylinositol ether lipids analogues. Cancer Res. 2004;64:2782-92.

\section{Discussion}

Dr Tom Waddell (Toronto, Ontario, Canada). Why do you think it was only tumoristatic given all the apoptosis you found in the explanted tumors?

Dr Rundall. On the TUNEL assay there were nests of apoptotic cells interspersed between cells that were at that time nonapoptotic, and so I think the net effect was a tumoristatic growth pattern, although, as you noted, there was significant apoptosis.

Dr David S. Schrump (Bethesda, Md). I congratulate you on a very clinically relevant study. I think it actually highlights the overlapping strategies that are now being used to combine histone deacetylase inhibitors with other small molecular compounds that are targeting NF- $\kappa$ B and survival pathways. Similar efforts have been under way with suberoylanilide hydroxamic acid and depsipeptide and combinations of other drugs, including LY or flavo- 
piridol, once again, to abrogate the survival pathways that are up-regulated paradoxically by histone deacetylase exposure.

I have just a couple of questions. The LY compound that you used, you imply that it is specific for the PI3/Akt pathway, but it really is also a PKC inhibitor. Do you have any data regarding the effects of this compound on PKC signaling in your model?

Dr Rundall. We looked at several pathways, but we did not look at PKC. We looked at the JNK, p38, MAPK, and DNA-PK pathways and inhibitors to those specific pathways and found that LY significantly reduced the butyrate-induced activation of PI3K/ Akt significantly more than any of the other pathways.

Dr Schrump. And both of those pathways will actually funnel through NF- $\kappa \mathrm{B}$, which is an upstream mediator of p21 and so forth. In your apoptotic experiment, which is very impressive in the in vivo model, did you look at p21 expression or anything else that is a known tumor suppressor up-regulated by histone deacetylase inhibitors that abrogates the cytotoxicity of these compounds? It is a nice translational end point to be looking at as well.

Dr Rundall. We did not look specifically at p21, but that is a good end point to evaluate.

Dr Schrump. And the last question, what happens if you withdraw therapy from those animals that had the combination drug treatment? Do any of those animals develop tumors?
Dr Rundall. We did not withdraw the drug. At that time we harvested the xenografts and analyzed them, but that would remain to be studied as well.

Dr Schrump. Thank you very much.

Dr Thomas A. D'Amico (Durham, NC). That was a nice presentation, and this continues on Dr Jones' long work on HD inhibition.

Would you comment on the clinical applicability of this strategy. How do we need to go from where we are now to the use of these agents in a phase I trial? Do you think that is a feasible goal?

Dr Rundall. There are several HDIs currently in phase I and II trials, and these are generally well tolerated. As far as the Akt/ PI3-kinase inhibitors, there is a significant amount of work being performed to develop more pharmacologically available compounds, as well as more specific inhibitors of Akt. There is a recent study by Phil Dennis at the National Cancer Institute where he reports 5 new water-soluble compounds that inhibit Akt suggesting that they could be used clinically.

Dr D'Amico. What are the toxicity issues with Akt inhibitors?

Dr Rundall. Specifically with LY there is skin necrosis at the site of injection, as well as decreased appetite and some malaise in the animals.

\section{Authoritative}

The Journal of Thoracic and Cardiovascular Surgery is the most frequently cited thoracic/cardiovascular surgery journal in the Science Citation Index. An article in JTCVS is cited on average almost twice as often as those in the closest cardiothoracic journal. 